\title{
The Counterproductive Effect of Pharmaceutical Marketing in Pakistan: A Qualitative Study
}

\author{
Dr. Fazle Malik \\ Field Manager Otsuka Pakistan Ltd Islamabad \\ fazalmalikopl@gmail.com \\ Dr. Muhammad Junaid \\ Assistant Professor Institute of Management Studies \\ University of Peshawar \\ mujunaidphd@gmail.com \\ Dr. Muhammad Asif \\ Assistant Professor, Management Sciences Department \\ City University of Science and IT, Peshawar, Pakistan \\ asifbaloch@cusit.edu.pk \\ Ilyas Sharif \\ Lecturer, Quaid eAzam College of Commerce \\ University of Peshawar \\ ilyas_acca@yahoo.com
}

\begin{abstract}
This study explores the effects of pharmaceutical marketing on patients and society in Pakistan. Pharmaceutical marketing is an integral part of the drug industry, which channels product-related information to healthcare professionals. Physicians are the target audience as they prescribe medicine to the users. The pharmaceutical industry mobilizes all resources to influence physicians' prescriptions in favor of their brands. It is commendable from the organizational perspective, however; it leads to unintended negative consequences for society. The primary reason is the blind pursuit of commercial interest and near-total neglect of ethical behavior in marketing drugs. This study conducted open-ended 20 interviews from primary stakeholders of this issue that includes physicians, pharmaceutical managers, and officials of drug regulatory authority through purposive sampling. The findings show that misleading promotional strategies influencing physicians are responsible for the misuse and abuse of drugs and antibiotics. Pharmaceutical drug incentivization, the personal obligation for physicians, skewed data, and inappropriate promotions were the major categories developed during analysis. The study recommends various steps to minimize these ill effects.
\end{abstract}

Key Words: Pharmaceutical marketing, marketing strategies, marketing ethics, ethical behaviors

\section{Introduction}

The discovery of antibiotics in the $20^{\text {th }}$ century is undoubtedly the defining milestone that has transformed human civilization (Brown \& Wright, 2016; Fischbach\& Walsh, 2009; Silver \&Bostian, 1993). It is responsible for the increase in the average age of humans. 
They are the most potent defense against a variety of bacterial infections in humans as well as animals and agriculture. The pharmaceutical industry is among the most researchintensive industries, which delivered continuous new products to the healthcare system and has saved lives and augmented quality of life (Scherer, 2000). Healthy collaborations between industry and academia further enrich the research and development work. Similarly, the discovery of antibiotics was not possible without the active role of the Pharmaceutical industry. After the discovery of antibiotics in the 1940s, the problem of infectious diseases drastically decreased in developed countries (Jones, Podolsky, \& Greene, 2012). It has also facilitated growth in animals and agriculture sectors (Cabello, 2006; Founou, Founou, \& Essack, 2016; Khachatourians, 1998). Therefore, antibiotics have a prominent role in the socio-economic development of advanced nations.

Pharmaceutical marketing is a vital element of the information continuum, where the ideas of research are transformed into pragmatic therapeutic tools and progressively molded for effective use in the healthcare system (Levy, 1994). Through marketing, pharmaceutical companies convey the appropriate message to healthcare professionals to help them in decision making. It contributes to $R \& D$ investment through motivation and anticipation of good prospects for the company and provides a beacon to make them more congruent with consumers' needs (Calfee, 2002). However, this competition can be detrimental to the very function of antibiotics as their overuse can result in their ineffectiveness. Promotion under the ambit of ethical codes enhances treatment standards and facilitates physicians in their decisions making. Marketing strategies are the key determinants of physicians prescribing behaviors (Davari, Khorasani, \& Tigabu, 2018); more the expensive strategy has a greater impact on persuading the target customers (Narendran \&Narendranathan, 2013). Well-designed strategies established profitable relationships with healthcare professionals. Physicians-industry interaction and giveaways acceptance is directly linked to physicians prescribing behaviors and irrational prescriptions (Fickweiler, Fickweiler, \& Urbach, 2017). In order to circumvent the undue influence of Pharmaceutical industry; self-regulation and institutional empowerment is vital (Grande, 2010). Adherence with the codes of concern international bodies and compliance with local laws may reduce the intensity of unethical promotions.

Over-promotion of pharmaceuticals lead to drug abuse and FDA has strictly forbidden physicians to advise medicine without proper indications (Wininger, 2004). According to an estimate, more than 2.2 million drug-related adverse reactions occur annually due to unnecessary prescription, of which antibiotics are the most commonly misused drugs (Lazarou, Pomeranz, \& Corey, 1998; Rabin, 2003). Every year more than 20000 people died of drug-related adverse reactions in the United States of America (Calabro, 2003). The indiscriminate use of antibiotics is a leading cause of developing and disseminating the resistant strains. Without concerted and coordinated efforts for prudent use of antibiotics, mankind is faced with the threat of "antibiotic apocalypse" (Brown \& Crawford, 2009; Cox \& Worthington, 2017; Nerlich\& James, 2009; Peattie \& Peattie, 2009) that lead to the rise of "untreatable bacteria" also called superbug (Alanis, 2005; Davies \& Davies, 2010; Ghafur, 2010; Kuehn, 2007; Washer \&Joffe, 2006; Wright, 2000). They adapt themselves rapidly to antimicrobials drugs and find new ways to survive against these drugs (Cox \& Worthington, 2017). This phenomenon is more dangerous than climate change because it can be very difficult to treat minor infections in the post-antibiotic era (Nerlich\& James, 2009). Superbugs are resistant to even the 
antibiotic of last resort (Bebell \& Muiru, 2014; Sengupta \& Chattopadhyay, 2012; Venter, Henningsen, \& Begg, 2017; Wozniak, Bailey, \& Graves, 2019). Pharmaceutical marketing is currently playing a major role in drugs overconsumption through its influence on physicians' prescribing habits.

\section{Research Questions}

1. How Pharmaceutical marketing influence physicians' prescription habits?

2. What strategies they employ to achieve their commercial objectives?

\section{Research Objectives}

1. To explore the influence of Pharmaceutical marketing on antibiotics resistance

2. To explorethe ethical aspects of Pharmaceutical marketing

\section{Literature Review}

Antimicrobials are the most commonly used drugs in the management of infectious diseases worldwide. The discovery of antibiotics in the early $20^{\text {th }}$ century has drastically changed the management of invading diseases that used to kill million in the preantibiotic era (Clardy, Fischbach, \& Currie, 2009). They have reduced the disease burden on national and international economies. The socio-economic role of antibiotics can't be ignored. Notwithstanding, the concrete progress in cure and prevention of infectious diseases, the parallel surge in AMR has seriously jeopardized the developments made in medical sciences and is the direct determinant of overuse and misuse of anti-microbes (Olivier, Williams-Jones, Doize, \&Ozdemir, 2010). Antibiotics are comparable to a fouredge sword in the fight against bacteria; the first two are treatment and prevention of contagious diseases; the third sword is the cost of the ineffectiveness of the drugs and the fourth is the collateral damage to the microbiota of an individual patients (Blaser, 2016). Misuse and abuse of these drugs have lost their effectiveness against bacteria. Lack of collaboration among academic institutions, industry, and government to discover new antibiotics; put the society at risk to infectious diseases and unsuccessful surgical procedures (Alanis, 2005). Many companies have deserted their research work on new antibiotics due to economic downturns and lack of government support.

According to an estimate the production of the global antibiotic is about 100000 per year; $80 \%$ is used in agriculture and animals as growth enhancers and prophylactic agents. Therefore, antibiotics enter into the environment, kill the useful bacteria of the microbiota, and put deleterious effects on the planet. The WHO warned member nations that massive overuse of current antibiotics; and lack of new research has led to highly resistant microbes or superbugs which affect the quality of lives of mankind (WHO, 2018). Poor regulatory mechanisms and lack of commitment from key stakeholders are contributing factors in the overuse and abuse of drugs. Mis-prescription, overprescription, patients' poor adherence with therapies, and its abuse in agriculture and aquaculture are the most common misuses of antibiotics (Costelloe, Metcalfe, Lovering, Mant, \& Hay, 2010; Goossens, Ferech, Vander Stichele, Elseviers, \& Group, 2005; Lee et al., 2014; Fazle Malik, 2019). Prescribing antibiotics in wrong indications; use against organisms other than bacteria (Butler, Rollnick, Pill, Maggs-Rapport, \& Stott, 1998; Faber, Heckenbach, Velasco, \&Eckmanns, 2010); and prescription under the influence of Pharmaceutical promotion are inappropriate (Cleary, 1992; Lopez- Vazquez, 
Vazquez- Lago, \&Figueiras, 2012; Power, 2006). Even in developed countries, $30 \%$ of prescriptions are unnecessary and inappropriate (Bren, 2002; Slomski, 2016; Zhang, Steinman, \& Kaplan, 2012). The major reasons for overconsumption of antibiotics are Pharmaceutical's aggressive marketing and non-professional approaches of physicians. The prescriptions of antimicrobials escalated in the 1990s due to aggressive marketing from the industry; resulted in overuse and hence the subsequent exacerbation of global antibiotic resistance (Bbosa, Mwebaza, Odda, Kyegombe, \&Ntale, 2014; Garcia-Rey, Aguilar, Baquero, Casal, \& Martin, 2002; Gaur \& English, 2006; McCaig, Besser, \& Hughes, 2002, 2003; McCaig, Hooker, Sekscenski, \&Woodwell, 1998). The burgeoning antimicrobial resistance was attributed to misuse and overuse of antibiotics which need immediate stewardships programs to be practiced by all concern stakeholders. Ethical behaviors are essential for the appropriate use of antimicrobials.

Surveillance of ethical and social issues is significant because they are not only contributing in antibiotic resistance but also possess huge potential in devising policy parameters. Avoiding this danger is not only a legal issue but has a strong ethical imperative. The role of ethics is central to this and the code of ethical conduct has been devised by various drug regulatory organizations e.g. IFPMA, WHO, ABPI, PhRMA, and others. The aim of these codes is to mitigate the pharmaceutical influence on the prescribing behaviors of physicians. Misleading promotion overstate products features and benefits while understating associated risks (Gottlieb, 2002). Healthcare professionals are more exposed to commercial evidence than robust scientific information (Peay\&Peay, 1988). Commercial forces play a significant role in adopting a drug by physicians rather than their professional competence. The marketers offer incentives to pharmacies to make drug sales profitable (Dua, Kunin, \& White, 1994). Selling more antibiotics means facilitating its consumption which is directly correlated with an increased resistance among pathogens. Therefore, the effectiveness of antibiotics substantially declines which is a serious threat for mankind and animals. Independently-monitored code of practice for marketers to ensure their ethical compliance and greater educational awareness for physicians and patients (Buckley, 2004) so as to promote ethical prescriptions and rational usage. It is in need of the hour to convince the key stakeholders that antibiotics are nonrenewable and a seriously at-risk resource (van den Bogaard \& Stobberingh, 2000), nonetheless, its judicious and prudent use is vitally important.

In majority of developing countries all most all drugs can be purchase from the counter with no check and balance (Ferguson, 1981; Geest, Whyte, \& Hardon, 1996; Goel, RossDegnan, Berman, \&Soumerai, 1996; Tomson \&Sterky, 1986; Trostle, 1996). Incapacitated institutions and the concerned authorities' lack of commitment are the main reasons behind this irregularity. Such availability of drugs leads to self-medication which is a principal cause of antibiotic resistance and WHO calls for immediate attention to curb it through proper legislation and forceful implementation (Etkin, 1992; Kunin et al., 1987; C. Kunin, 1983). The pharmaceutical industry encourages pharmacies to sell their products over-the-counter (OTC) by offering various lucrative incentive schemes. The sales of antibiotics and some other controlled drugs as OTC have very serious repercussions like AMR, allergic reactions, toxic posing, and other drug-related events (Kamat\&Nichter, 1998). Institutional intervention is necessary to formulate proper legislative measures to curb such malpractices. The inappropriate and imprudent use of antibiotics has further exacerbated the ingenuity of bacteria to withstand their 
effectiveness. Currently the pandemic of AMR is prevailing throughout the world including America, Europe, Africa, Asia, and Australia. The resistive pathogens have the innate ability to spread with an unexpectedly high speed and the contemporary communication channels have further accelerated it. There are multiple surveillance reports which substantiate the association between antibiotic resistance and its overuse (Goossens et al., 2005; Van De Sande-Bruinsma et al., 2008). Thus, decreasing overuse can mitigate the issue of AMR.

\section{Aggressive Promotional Practices}

The prescriptions of antimicrobials escalated in the 1990s due to aggressive marketing from the industry; resulted in overuse and hence the subsequent exacerbation of global antibiotic resistance (Bbosa et al., 2014; Garcia-Rey et al., 2002; Gaur \& English, 2006; McCaig et al., 2002, 2003; McCaig et al., 1998). Several antibiotics become victims of their excessive use in the very early stage of their launch. It is estimated that $50 \%$ of antimicrobials are used inappropriately which is linked with irrational prescription; prolong the duration of treatment; erroneous dosage; and use in wrong indications (Usluer, Ozgunes, \&Leblebicioglu, 2005). Nevertheless, promotional activities can compel physicians to advise drugs in the wrong indications and encourage their sales over-the-counter. Ethical compliance can be a worthy framework to enforce ethical principles in its spirit to bring about social responsibility in makers' behaviors. The Codes of ethics framed by the International Federation of Pharmaceutical Manufacturers (IFPMA) stressed self-regulation for member companies (Wager, 2003). The document emphasized maintaining a high standard in the promotion of drugs to physicians' strict compliance with the host country's laws. The marketing practices of the industry should promote the rational use of drugs to maintain healthy public health and minimize drugrelated adverse effects. Transparency, honesty, integrity, and fairness should be the hallmarks Pharmaceutical marketing practices (WHO, 1988). Trustworthiness in marketing is not only pivotal for marketers but also for building the goodwill of the firms. Nonetheless, generously spending on physicians and health workers increases the chances of unethical behaviors.

Pharmaceutical spend a huge amount of money on marketing their products, which is an attractive investment (Bbosa et al., 2014; WHO, 2005). Figure\#1 shows that majority of the budgets are spent on personal selling or detailing, sponsorships (conferences, abroad/local tours, CME, meals), giveaways, product sampling, clinical trials, and advertisement in specific journals (Sufrin\& Ross, 2008). The massive promotion of antibiotics is an important contributor to increase prescriptions without keeping in view their side effects (Brand, 2008; Wazana, 2000). Nevertheless, antibiotic usage is interrelated to antibiotic resistance. Increasing the imprudent use will develop more resistance in bacteria and consequently dangerous repercussions for humankind. 
Figure:1 Pharmaceutical Marketing Promotional Spending

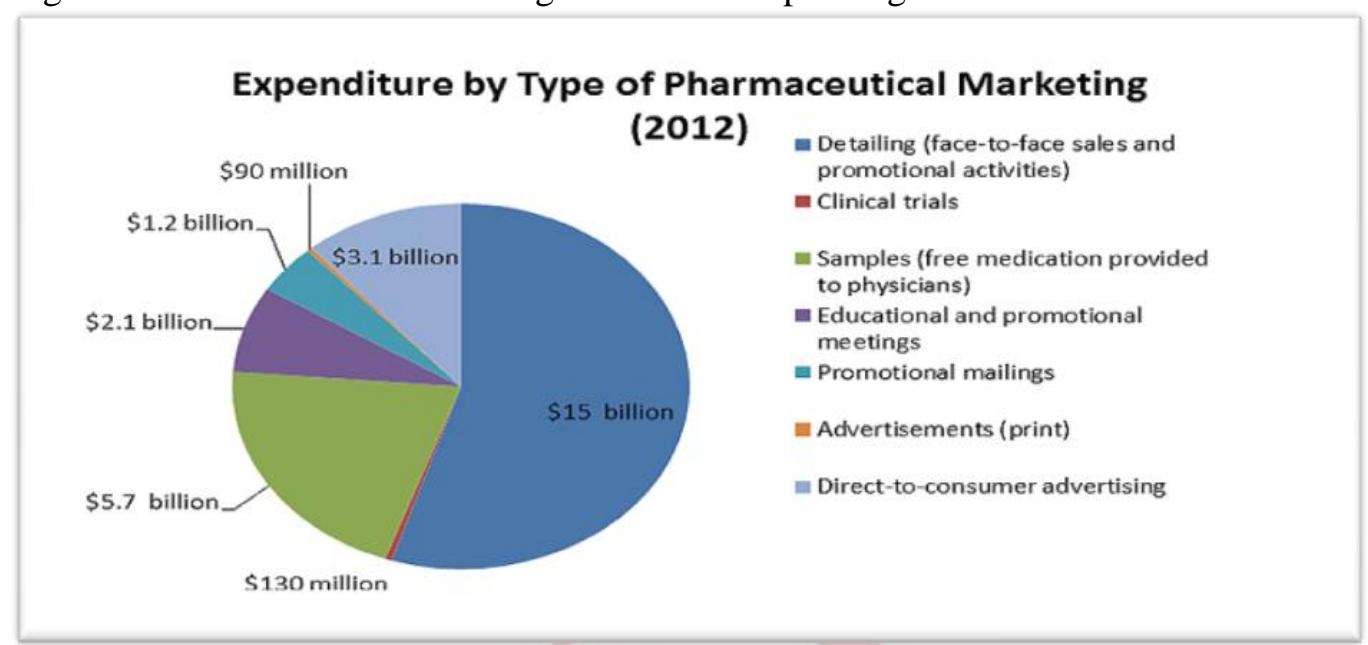

Source: Cegedim Strategic Data, 2012 U.S. Pharmaceutical Company Promotion

Spending(Bbosa et al., 2014, p. 415).

The increase global spending on marketing is a clear manifestation of over-promotion of drugs in the form of over-prescriptions and over-the-counter sales which are leading causes of AMR. The significance of marketing is evident from the fact industry has pushed back R\&D and diverted their energies and investment in marketing. That's why the directors of marketing are very prominent personalities in the organizations while that of R\&D has lost their importance.

\section{Research Methodology}

This study adopts a qualitative approach to empirically grasp the nexus between the current pharmaceutical marketing practices and antimicrobial resistance. Here qualitative research design provides comprehensive tools to investigate the phenomenon under study (Patton, 2002) by permitting priority to the population's interpretations. In social sciences, the vitality of subjectivity matters a lot because it allows an in-depth analysis of the phenomenon (Krefting, 1991; Schmid, 1981). Each member of the population has a different meaning about the existing Pharmaceutical practices and their subsequent influence on antimicrobial resistance. Grounded theory is applied as a strategy of inquiry to obtain rich insights from different dimensions. GT is most appropriate because the inquirer intends to reach into the phenomenon from different perspectives. Antibiotic resistance is a global issue and inductively investigation lead to meaningful and insightful theory building (Eisenhardt, Graebner, \&Sonenshein, 2016). Interpretivist stance is adopted to socially construct the phenomenon (Gephart, 2004) where physicians, pharmacists, and salespeople experiences are presented authentically and faithfully. Nevertheless, concepts investigating inductively either gave sense-making or sense-giving (Eisenhardt et al., 2016). Theoretical sampling was practiced by the researcher where data from a small sample size was collected and analyzed. Then the further sample was selected in light of themes and categories developed in the first step. Data collected and analyzed until reaching maturity. This back and forth movement in sampling, data collection, and analysis is a theoretical sampling. Theoretical sampling is the hallmark of 
GT which select a sample on the basis of its ability to illustrate and establish relationships among the themes and categories and thus helpful in in-depth insights of the concepts (Eisenhardt\&Graebner, 2007). The outcomes of inductive research is the emergent of coherent and parsimonious theory; themes and categories grounded in data and rich insights of the constructs. Systematic and structured techniques are employed to generate theory from social settings (Glaser \& Strauss, 1967). That is theory grounded in the data collected in the fieldwork of the researcher. Grounded theory research "is a continuous process of data collection, followed by analysis and memo writing, leading to questions, that lead to more data collection, and so on" (Corbin, Juliet, \& Strauss, 2014, p. 197). GT method was used to collect data from the participants in their contexts through in-depth interviews, observations, and experiences.Constant comparison is the hallmark of grounded theory where data is compared with data, categories, and subcategories (Holloway \& Wheeler, 2002). In this method, there is a correlation between data collection and analysis. Initially, data are collected which is analyzed meticulously, from this analysis the concept is derived which becomes a basis for subsequent data collection (Corbin et al., 2014). The method was used to investigate the constructs of marketing and macro-marketing for theory generation (Dholakia \&Nason, 1984; Hunt, 1994). Research questions having why, what, and how are easily answered by GT (Charmaz, 2008).

The population of this research constitutes Pharmaceutical managers, DRAP concern employees, and physicians in District Peshawar. There are no strict rules for the sample size because the saturation of categories is the criteria for sufficiency. The sampling technique used was purposive which is aided by snowball sampling (Cassell\& Symon, 2004). To incorporate more depth and richness in data the interviews were conducted through open-ended questions. The researcher transcribed the in-depth field interviews to make them suitable for analysis. The analysis process starts with naming and categorizing of texts (Cassell\& Symon, 2004). The microanalysis of data took place word-by-word and paragraph-by-paragraph (Moghaddam, 2006). Open coding is the kickoff of the coding process, which further breaks down data into discrete dimensions (Goulding, 2002; Strauss \& Corbin, 1998). The researchers established strategic connectivity established between emerging theory and data collected.

\section{Findings of the Study}

Marketing strategies enacted by Pharmaceutical industry are debatable and need thorough scrutiny. Continuing medical education (CME) is used as a tool of inducing sales and profits which appalled its credibility and integrity (Relman, 2001). Marketers devised targeted promotional programs for key opinion leaders (KOL's) to win their support in products patronization (Fava, 2008). Industry paid them prodigally according to their potential and relevant influence in their respective specialties (Moynihan, 2008). Therefore, the use of drugs explicitly antibiotics inflated which directly linked with deleterious side effects in end users. The prime objective of qualitative data analysis is to identify the underlying theme that's developed with four categories. 
Table:2 Theme and Categories

\begin{tabular}{ll}
\hline S.No & Theme and Categories \\
\hline $\mathbf{1}$ & Misleading Promotional Strategies Influencing Physicians \\
& 1. Pharmaceutical Drug Incen \\
2. tivization \\
3. Personal Obligations; an Overarching Strategies \\
4. Data are misrepresented and skewed \\
5. Inappropriate Promotion lead to Unnecessary Prescription
\end{tabular}

\section{Controversial Promotional Strategies}

The primary objective of Pharmaceutical marketing is to apprise healthcare professionals on contemporary developments in medical field. However, this conceptualization markedly overlooked and the peer-reviewed data molded for their products that ultimately violate the ethical principles of marketing. In the pursuit of sales, they expand treatment boundaries to enhance drugs usage in diseases (Moynihan, 2002). Academic conferences are sponsor for their stakes, because increases prescriptions have been observe after such sponsorships. The Pharmaceutical industry of Pakistan is grappling for top positions in national ranking to captivate potential investors. Nevertheless, securing a firm placement in national ranking is debatable if it obtained because of increase antibiotic sales. Conflict of interest arises when stakeholder genuinely creates problems for the other. Pharmaceutical companies and physicians are working against the norms of social contracts that stress on the very importance of each stakeholder. This study explores that industry has crossed ethical limits in generating prescriptions from physicians to produce huge sales volumes and profitability on the expense of iatrogenic effects in patients.

\section{Financial Attraction in Products}

Pharmaceutical marketing lure drugs through incentive schemes to stimulate prescriptions and usage in the market. Industry pushes their products through bonus schemes for their prime customers, which produces a large sum of profits. Nonetheless, such lucrative allures trigger imprudent prescriptions from physicians, which are hazardous for patients. It has been proved that drugs incentivization generate sales volumes and profits but escalates unethical practices. Professionals who are seeking only financial benefits in antibiotics lead to antimicrobial resistance (R3, R8). Therefore, physicians acquisitive behaviors may earn them profits but patients' wellbeing is left behind which is unconscionable approach (R4, R10). Majority of the respondents were of the opinion that producing high sales is a sign of incorporating more side effects in human body in the form resistance in bacteria.

"...selling more active ingredients in the market means that producing more side effects, if the use is not evidently prudent. If resistance is developing in the population, they will not sell more antibiotic of the same types" (R3, line\#185).

The insensitive and imperceptible attitude of physicians put materialism on priority and pushing behind the patients' care. This attitude endangers the credibility and integrity of physicians and lead to vilification of medical profession. Meanwhile, the malpractices in the discipline of marketing need to be improve to attenuate its impact on the larger society and environment. 


\section{Personal Obligations; an Overarching Strategies}

The importance of ethics in business increase many folds in recent years due to frequent frauds and corruptions in some corporations. Therefore, public trust sharply decreased due to their all-consuming attitude and selfishness. Same is the behavior of Pharmaceutical industry, which is skeptical and mostly oriented towards self-interests. Personal obligation is an integral part of marketing program to provide personalized services to influential members of the medical community in return of products patronization (R2, R5). This reduces the rational approach of physicians and drugs may be prescribed in cases where there is no need (R1, R4, R13). Consequently, this unethical approach may lead to irrational use of drugs which manifest in the form of AMR in infectious disease patients $(\mathrm{R} 3, \mathrm{R} 4)$. In healthcare profession, evidence based prescription relieved the sufferings of patients and eradicate disease, which repositioned it in the mind of ailing humanity. Rational prescriptions not only enhance physicians' ethical adherence but also avoid side effects and timely recovery of patients. The essence of this category is that the current pharmaceutical marketing has focus on personal obligations to key opinion leaders to obtain their commitment not only in product patronization but influencing other colleagues of the same field.

\section{Misrepresented and Skewed Data}

Product related data and associated references are proportional physicians' prescriptions. There is also a statistical significance of these information on physicians' prescribing behaviors (Mizik \& Jacobson, 2004). The selection of a drug in prescriptions is based on robust evidences, which are published world-renowned medical journals. However, these research trials and publication are often skew and shape to favor their products. They portray the product related part and leave behind other, which is important for medical profession. The drug-related adverse effects are not share with doctors to further sharpen their prescription choice. The product related information provided by medical representatives is unsubstantiated, manipulated, obsoleted and incomplete, thus, unsupportive in rational use of drugs (R1, R5, R12). It is mandatory for industry to use those references that are consistent with WHO guidelines and other bodies (R8, R13). Nevertheless, multinational companies convince physicians on the basis authentic data with determine sources and aid in rational product patronization (R11, R13). However, the democratization of information has changed the worldand physicians are now mostly rely on online sources (Fazal Malik, Asif, \& Wali, 2016).

"Multinational companies are not making any manipulation in their information because their parents' companies are very strict in ethical conducts" (R12, line\#313).

Physicians are persuaded on the basis on solid evidences. The studies should be considered for promotional help, which is published in high impact journal otherwise.

\section{Inappropriate Promotion lead to Unnecessary Prescription}

Healthcare professionals prescribed antibiotics in non-indicated diseases with wrong dosage, which results in antimicrobial resistance (Greenhalgh, 1987). The misuse of not only attributed to physicians' malpractices but patients also ask for this very drug during consultation (Palmer \&Bauchner, 1997; Paluck et al., 2001). There is myriad of literature that patients inappropriately demand for these wonderful drugs for their early recovery (Bauchner et al., 1999; Mangione-Smith et al., 1999; Schwartz et al., 1997). However, 
physicians and pharmacists are technically experts enough to choose the targeted antibiotics for each patient. Most of the respondents expressed their dissatisfaction on questionable behaviors of physicians, which is reflected in the form of unnecessary prescriptions of drugs to patients manifested in the form of AMR and other concomitant side effects (R1, R2, R7, R16). Usually they advise broad spectrum of antibiotics in common infectious diseases that violate the established protocols (R4, R9). Pharmaceuticals are active molecules and unnecessary use may produce side effects in body that further aggravate patients' conditions (R6, R11). Poly-pharmacy not only increases the chances drug-drug interactions but also an economic loss for patients (R10, $\mathrm{R} 11, \mathrm{R} 14)$. Conspicuously, majority of the respondents revealed that over-promotion, physicians' self-centeredness and patients' psychological factors are responsible for misuse and even abuse of antibiotics in Pakistan.

"The ...concern company has extended some bribes and other facilities for the doctor who was very interested to prescribe in non-indicated cases" (R2, line\#49). “...they are advising drugs without indications. Patients don't need multivitamins or antibiotics and doctors are regularly prescribing" (R3, line\#117).

The immunity engulfs the foreign invading microorganisms to some extent but antibiotics help to either kill these bacteria or halt their growth. Therefore, appropriate antibiotic with proper dosage is a blessing for main kind. Nevertheless, misuse and abuse of such drugs lead to many complications in patients, which cripple their condition even further. The healthcare system of Pakistan is already in doldrums and malpractices of industry and physicians further complicate the situations. There is a dire need to proscribe the practices of quackery in Pakistan; developed appropriate guidelines for the discipline of marketing; reframed laws to govern the behaviors of physicians. Physicians' compliance may be ameliorated through implementation of suitable code of ethics and international treatment protocols.

\section{Discussion and Conclusion}

Pharmaceutical marketing adapts various promotional strategies for their products and services. The aim is to increase sales volumes and profitability for shareholders. Studies show that misleading promotional strategies are linked to increasing irrational prescriptions of physicians, which lead to antibiotics resistance. Firstly, the discipline entices products/services through product incentivization which altered consumption patterns. They focus on commercial aspects of promotional activities and put behind the social dimensions, which prerequisites for the smooth functioning of the society. They are entitling themselves as disease mongers because they intentionally expand treatment boundaries for their products (Wolinsky, 2005). Secondly, the industry establishes profitable relationships with potential physicians through personal obligations. The conflict of interest arises when physicians accept giveaways and sponsorships from marketers, which provoke the law of reciprocity (Dana \&Loewenstein, 2003; Katz et al., 2010). The industry exploits the loopholes among the medical community. Thus, it can be concluded that Pharmaceutical marketing is involved in questionable practices that led to over-prescription and over-consumption of drugs particularly antibiotics.

Thirdly, the references and data to convince physicians through solid evidence basis are skewed and fabricated.The information presented to physicians by sales reps are biased; escalates prescription cost for patients and responsible for suboptimal consumption of 
drugs (Fugh-Berman \&Ahari, 2007; Haayer, 1982; Ziegler et al., 1995). Therefore, physicians' prescription decision is not relying on marketers' data but rather search for other sources as well. Fourthly and finally, inappropriate prescriptions from physicians are common practice due to poor adherence to medical guidelines and codes of ethics. Poly-pharmacy irrational prescriptions, self-medications, wrong dosage, and inappropriate use of antibiotics are a common practice in developed and developing countries. Unprofessional behaviors of healthcare workers; lack of suitable regulations and enforcement of existing laws and poor awareness on the part of patients are the leading causes of misuse of antibiotics. It is shown in the following diagram \#1. Irrational prescription is a leading cause of antibiotic resistance and increases the misuse of drugs

Diagram: 1 the Effects of Promotional Strategies on Antibiotics Resistance

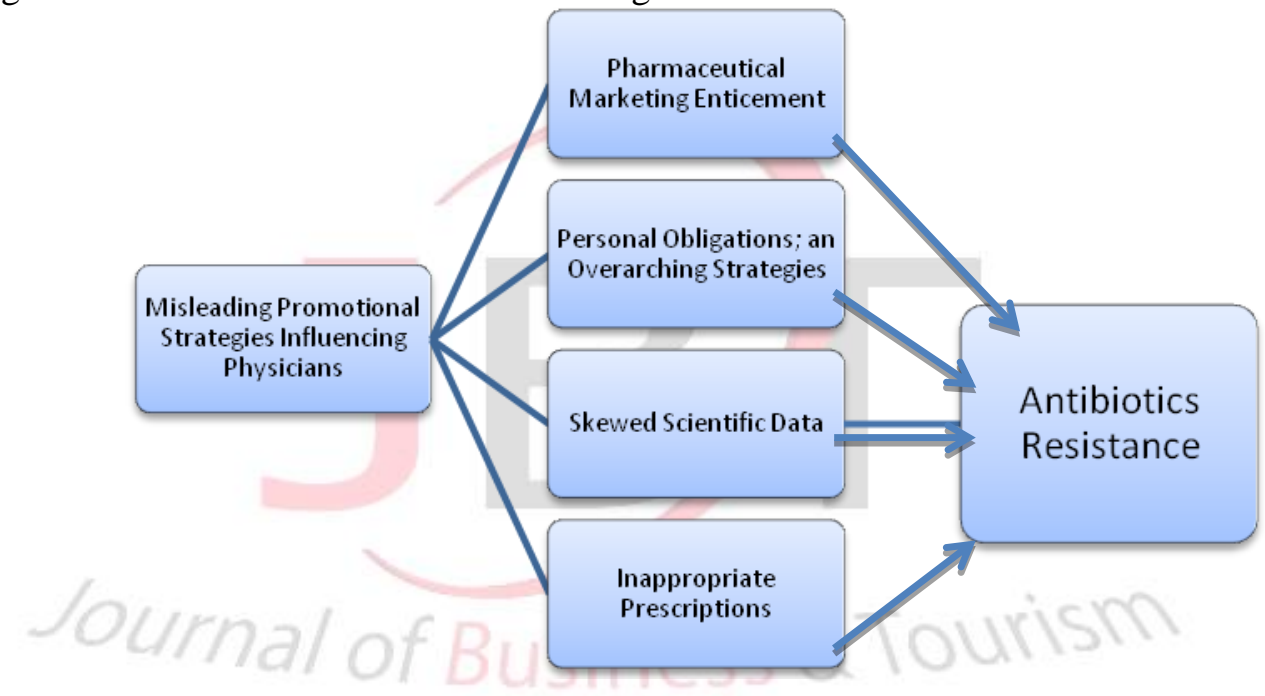

\section{Pharmaceutical Marketing Enticement}

The burgeoning usage of antibiotics has led to the antibiotics apocalypse that seriously affecting public health worldwide (Van Boeckel et al., 2014). The quest for antibiotic of last-resort increases day by day because majority of bacteria are immune to this wonderful drug. These unsusceptible microbes are difficult to eliminate, therefore, they become life threatening for human. The efforts of international national bodies should be consolidated to prohibit the imprudent use of antibiotics not only in human but also in animal and agricultures sectors. Antibiotic stewardship programs may ameliorate the current treatment process (Di Pentima\& Chan, 2010). Pharmaceutical business is not a sustainable one because resistance is develop in bacteria that will greatly affect the future generations. During interviews, one respondent elaborate that industry is involved in cannibalizing activity because they create resistance for their products in the market. Notwithstanding, transparent, ethical and moral promotion of antibiotics is a true service to public health. 


\section{Personal Obligations}

Key opinion leaders are the linchpins of Pharmaceutical marketing due to their dual support in sales; they regular prescribers of the company's products; junior doctors consistently following them. So, they create a significant impact in building company image and generating sales volume. Therefore, marketers design strategies and tactics to convert them in to loyal users (Sismondo, 2013). It is noteworthy that physicians and industry are important pillars of healthcare system and their ethical coordination and collaboration remarkably improve patients' quality of lives (Jibson, 2006). But unethical interactions of Pharmaceutical marketing are continuously corrupting physicians (Buckwell, 2008). However, healthcare professionals are indebted to scientific technologies, products and services provided on Pharmaceutical industry. The respondents from both medical community and Pharmaceutical marketing remarked that the emphasis of industry is on the top-notched physicians to win their word-of-mouth promotion. They apply all possible resources and techniques to make them advocates for the company's products and services.

"...but we are helpless to convince doctors on the basis of evidence and studies because they are habitual to personal obligations. They always ask to do something personally for them" (R11, line\#146).

\section{Skewed Scientific Data}

Pharmaceutical marketing is the exchange of drugs-related information between medical representatives and physicians to provide a solid foundation for rational prescriptions (Rod \& Saunders, 2009). This exchange takes place in medical representative detailing in front of doctors that lead to a fruitful discussion. As a result, the targeted doctors convince to either patronize or vice versa (Narayanan et al., 2004). In advanced countries physicians' value medical representatives and considered them a reliable source of knowledge while in developing world they are undependable (Murshid Mohsen, 2017). Therefore, the focus of Pakistani industry is on sponsorships of CME and academic conferences to take maximum business share from potential doctors. It has found that sales of particular companies increase after sponsorships of CME and conferences that question their credibility and integrity (Relman, 2001). Nevertheless, some multinational companies extend foreign sponsorship purely based on merits and favor only their academic values.

The prescription decision should be based on scientific evidences to avoid side effects and improve patients' treatment outcomes. However, the current studies are not reliable because they either withhold the negative outcomes of trials or suppressed it to use in the best interests of products and company (Spielmans \& Parry, 2010). Furthermore, they use obsolete data or references from spurious journals.

"...Either the references are too old or of low standard. They are not from standard journals"

The multinational companies operating in Pakistan are doing ethical business, play the game on the basis well authentic data, and use journals of good impact factors.

"Multinational companies are not making any manipulation in their information because their parent's companies are very strict in ethical conducts" (R12, line\#313). 


\section{InappropriatePrescriptions}

In Pakistan, physicians are the sole authority in advising medicines to patients without interruptions. Therefore, the center of interests for Pharmaceutical marketing is physicians. They design, develop and formulate marketing strategies to convince as many as physicians for their products and services. This over-promotion causes abuse of drugs which WHO and other international bodies strictly forbid (Wininger, 2004). This focus of attention towards physicians, influence their prescriptions habits and is a major cause of unnecessary prescription (McCaig\& Hughes, 1995; Paluck et al., 2001). Even, patients may ask for a potent and expensive antibiotic for fast recovery (Chretien et al., 1975; Palmer \&Bauchner, 1997). Consequently, the prescription does not remain rational and shepherd resistance in bacteria that causes infections.

\section{Conclusion and Managerial Implications}

The primary aim of Pharmaceutical marketing, is to impart all details of their products and services to healthcare professionals to support them in making an inform decision for patients. Ethical and moral dimensions must be kept in mind to prevent the misuse of drugs. The international bodies like IFPMA, PhRMA, ABPI and APMA are vigorously working to devise guidelines and codes of ethics for marketers. Nevertheless, marketers' adherence to these codes of ethics is very poor because their commercial objectives overweigh their social and moral principles (Mali et al., 2010). Pharmaceutical marketing is different than other marketing disciplines because the target audiences are not the users (Lexchin\&Kawachi, 1996). Physicians are the prescribers, pharmacies are the purchasers while patients are the end users so codes of conducts and regulatory frameworks are the only tools to control these stakeholders.

Physicians are the linchpins of healthcare system and they provide health services to public without race, ethnic and religious background. They transform hospitals to caring and curing centers. However, the current workers are inept in skills and technique and incredible in character. The respondents conspicuously point out that they are selfcentered, materialistic and not patient-centric. Medicines are other integral parts of this system but their irrational use is ubiquitous. As result, produce major risks for patients and loss of scarce resources (Ofori-Asenso\&Agyeman, 2016). Rational prescriptions and responsible dispensing of drugs should be implemented to avoid the concomitant hazards with them.

True marketing professionals not only nurture their own skills and characters but also influence their target audience behaviors. Instead of looking for loopholes, they should inspire to work jointly for patients' benefits. However, they have manipulated physicians by offering lucrative bonus schemes and incentives on products or services uses. Numerous studies found out that irrational prescriptions are common across all specialties (Das et al., 2001; Kuruvilla et al., 1994; William et al., 2003). If antibiotics and other controlled drugs are irrationally advice to patients, they usher AMR in them. The literature is also replete of studies which indicate that inappropriate prescription is a leading cause of antibiotic resistance and the situation can be improve only when each stakeholder respect the social contracts exist among them.

The discipline of marketing can be successful in Pharmaceutical industry if it is multivoiced bring different stakeholders in to a single table to incorporate many perspectives in to it. With more collaboration and coordination, the ethical discourse of marketing can be 
lead in to new heights where it will bring more prosperity not only for organizations but also for the whole community. Managerialimplications are executing ethical compliance in marketing and clinicalpractices. Ethical behaviors for both marketers and physicians are important tobenefit patients and the healthcare system. Adherence to codes of conduct inmarketing is essential for sales people. Educational and awareness programs must bedevised for concerned stakeholders to bring harmony in their behaviors.

\section{References}

Alanis, Alfonso J. (2005). Resistance to Antibiotics: Are We in the Post-Antibiotic Era? Archives of Medical Research, 36(6), 697-705. doi: https://doi.org/10.1016/j.arcmed.2005.06.009

Bbosa, Godfrey S, Mwebaza, Norah, Odda, John, Kyegombe, David B, \& Ntale, Muhammad. (2014). Antibiotics/antibacterial drug use, their marketing and promotion during the post-antibiotic golden age and their role in emergence of bacterial resistance. Health, 6(05), 410.

Bebell, Lisa M, \& Muiru, Anthony N. (2014). Antibiotic use and emerging resistance: how can resource-limited countries turn the tide? Global heart, 9(3), 347-358.

Blaser, Martin J. (2016). Antibiotic use and its consequences for the normal microbiome. Science, 352(6285), 544-545. doi: 10.1126/science.aad9358

Brand, Rachel. (2008). Marketing drugs: debating the real cost. Concern about close ties between doctors and pharmaceutical firms are prompting new financial disclosure laws and education efforts. State legislatures, 34(8), 26.

Bren, Linda. (2002). Battle of the bugs: fighting antibiotic resistance. FDA consumer, $36(4), 28$.

Brown, \& Crawford, Paul. (2009). 'Post antibiotic apocalypse': discourses of mutation in narratives of MRSA. Sociology of health \& illness, 31(4), 508-524.

Brown, \& Wright, Gerard D. (2016). Antibacterial drug discovery in the resistance era. Nature, 529(7586), 336.

Buckley, Joan. (2004). Pharmaceutical marketing-time for change. EJBO-Electronic Journal of Business Ethics and Organization Studies.

Butler, Rollnick, Stephen, Pill, Roisin, Maggs-Rapport, Frances, \& Stott, Nigel. (1998). Understanding the culture of prescribing: qualitative study of general practitioners' and patients' perceptions of antibiotics for sore throats. Bmj, 317(7159), 637-642.

Cabello, Felipe C. (2006). Heavy use of prophylactic antibiotics in aquaculture: a growing problem for human and animal health and for the environment. Environmental Microbiology, 8(7), 1137-1144. doi: 10.1111/j.1462-2920.2006.01054.x

Calabro, Sheryl. (2003). Breaking the shield of the learned intermediary doctrine: Placing the blame where it belongs. Cardozo L. Rev., 25, 2241.

Calfee, John E. (2002). The Role of Marketing in Pharmaceutical Research and Development. PharmacoEconomics, 20(3), 77-85. doi: 10.2165/00019053200220003-00008

Cassell, Catherine, \& Symon, Gillian. (2004). Essential guide to qualitative methods in organizational research: Sage.

Charmaz, Kathy. (2008). Constructionism and the grounded theory method. Handbook of constructionist research, 397-412. 
Clardy, Jon, Fischbach, Michael A, \& Currie, Cameron R. (2009). The natural history of antibiotics. Current biology, 19(11), R437-R441.

Cleary, John D. (1992). Impact of pharmaceutical sales representatives on physician antibiotic prescribing. Journal of Pharmacy Technology, 8(1), 27-29.

Corbin, Juliet, \& Strauss, Anselm. (2014). Basics of qualitative research: Sage.

Costelloe, Ceire, Metcalfe, Chris, Lovering, Andrew, Mant, David, \& Hay, Alastair D. (2010). Effect of antibiotic prescribing in primary care on antimicrobial resistance in individual patients: systematic review and meta-analysis. Bmj, 340, c2096.

Cox, Jonathan AG, \& Worthington, Tony. (2017). The 'Antibiotic Apocalypse'Scaremongering or Scientific Reporting? Trends in microbiology, 25(3), 167-169.

Davari, Majid, Khorasani, Elahe, \& Tigabu, Bereket Molla. (2018). Factors Influencing Prescribing Decisions of Physicians: A Review. Ethiopian journal of health sciences, 28(6), 795-804. doi: 10.4314/ejhs.v28i6.15

Davies, Julian, \& Davies, Dorothy. (2010). Origins and evolution of antibiotic resistance. Microbiol. Mol. Biol. Rev., 74(3), 417-433.

Dholakia, Nikhilesh, \& Nason, Robert W. (1984). Research Issues in Macro-Marketing: A Blueprint for Progress. European Journal of Marketing, 18(1), 41-55. doi: doi:10.1108/EUM0000000004720

Dua, Vikram, Kunin, Calvin M, \& White, Laura VanArsdale. (1994). The use of antimicrobial drugs in Nagpur, India. A window on medical care in a developing country. Social science \& medicine, 38(5), 717-724.

Eisenhardt, Kathleen M., \& Graebner, Melissa E. (2007). Theory Building From Cases: Opportunities And Challenges. Academy of Management Journal, 50(1), 25-32. doi: 10.5465/amj.2007.24160888

Eisenhardt, Kathleen M., Graebner, Melissa E., \& Sonenshein, Scott. (2016). Grand Challenges and Inductive Methods: Rigor without Rigor Mortis. Academy of Management Journal, 59(4), 1113-1123. doi: 10.5465/amj.2016.4004

Etkin, Nina L. (1992). "Side effects": cultural constructions and reinterpretations of western pharmaceuticals. Medical Anthropology Quarterly, 6(2), 99-113.

Faber, MS, Heckenbach, Kirsten, Velasco, Edward, \& Eckmanns, Tim. (2010). Antibiotics for the common cold: expectations of Germany's general population. Eurosurveillance, 15(35), 19655.

Fava, Giovanni A. (2008). Should the drug industry work with key opinion leaders? No. BMJ, 336(7658), 1405-1405.

Ferguson, Anne E. (1981). Commercial pharmaceutical medicine and medicalization: a case study from El Salvador. Culture, medicine and psychiatry, 5(2), 105-134.

Fickweiler, Freek, Fickweiler, Ward, \& Urbach, Ewout. (2017). Interactions between physicians and the pharmaceutical industry generally and sales representatives specifically and their association with physicians' attitudes and prescribing habits: a systematic review. BMJ open, 7(9), e016408.

Fischbach, Michael A, \& Walsh, Christopher T. (2009). Antibiotics for emerging pathogens. Science, 325(5944), 1089-1093.

Founou, Luria Leslie, Founou, Raspail Carrel, \& Essack, Sabiha Yusuf. (2016). Antibiotic Resistance in the Food Chain: A Developing Country-Perspective. Frontiers in Microbiology, 7(1881). doi: 10.3389/fmicb.2016.01881 
Garcia-Rey, C, Aguilar, L, Baquero, F, Casal, J, \& Martin, JE. (2002). Pharmacoepidemiological analysis of provincial differences between consumption of macrolides and rates of erythromycin resistance among Streptococcus pyogenes isolates in Spain. Journal of clinical microbiology, 40(8), 2959-2963.

Gaur, Aditya H, \& English, B Keith. (2006). The judicious use of antibiotics-An investment towards optimized health care. The Indian Journal of Pediatrics, 73(4), 343-350.

Geest, Sjaak van der, Whyte, Susan Reynolds, \& Hardon, Anita. (1996). The anthropology of pharmaceuticals: a biographical approach. Annual review of anthropology, 25(1), 153-178.

Gephart. (2004). Qualitative Research and the Academy of Management Journal. Academy of Management Journal, 47(4), 454-462. doi: 10.5465/amj.2004.14438580

Ghafur, AK. (2010). An obituary - on the death of antibiotics. J Assoc Physician India, 58(3), 143-144.

Glaser, \& Strauss. (1967). The discovery of grounded theory Chicago. Adeline, USA.

Goel, P, Ross-Degnan, D, Berman, P, \& Soumerai, S. (1996). Retail pharmacies in developing countries: a behavior and intervention framework. Social science \& medicine, 42(8), 1155-1161.

Goossens, Herman, Ferech, Matus, Vander Stichele, Robert, Elseviers, Monique, \& Group, ESAC Project. (2005). Outpatient antibiotic use in Europe and association with resistance: a cross-national database study. The Lancet, 365(9459), 579-587.

Gottlieb, Scott. (2002). Congress criticises drugs industry for misleading advertising. BMJ (Clinical research ed.), 325(7377), 1379-1379. doi: 10.1136/bmj.325.7377.1379/a

Goulding, Christina. (2002). Grounded theory: A practical guide for management, business and market researchers: Sage.

Grande, David. (2010). Limiting the influence of pharmaceutical industry gifts on physicians: self-regulation or government intervention? Journal of general internal medicine, 25(1), 79-83. doi: 10.1007/s11606-009-1016-7

Holloway, Immy, \& Wheeler, Stephanie. (2002). Qualitative research in nursing: WileyBlackwell.

Hunt. (1994). On Rethinking Marketing: Our Discipline, Our Practice, Our Methods. European Journal of Marketing, 28(3), 13-25. doi: doi:10.1108/03090569410057263

Jones, David S., Podolsky, Scott H., \& Greene, Jeremy A. (2012). The Burden of Disease and the Changing Task of Medicine. New England Journal of Medicine, 366(25), 2333-2338. doi: 10.1056/NEJMp1113569

Kamat, Vinay R, \& Nichter, Mark. (1998). Pharmacies, self-medication and pharmaceutical marketing in Bombay, India. Social science \& medicine, 47(6), 779-794.

Khachatourians, George G. (1998). Agricultural use of antibiotics and the evolution and transfer of antibiotic-resistant bacteria. Cmaj, 159(9), 1129-1136.

Krefting, Laura. (1991). Rigor in qualitative research: The assessment of trustworthiness. American journal of occupational therapy, 45(3), 214-222. 
Kuehn, Bridget M. (2007). Antibiotic-resistant "superbugs" may be transmitted from animals to humans. JAMA, 298(18), 2125-2126.

Kunin, Lipton, Helene L, Tupasi, Thelma, Sacks, Theodore, Scheckler, William E, Jivani, Amir, .. . Thamlikitkul, Visanu. (1987). Social, behavioral, and practical factors affecting antibiotic use worldwide: report of Task Force 4. Reviews of infectious diseases, 9(Supplement_3), S270-S285.

Kunin, CM. (1983). Micro drug research. Annals of Internal Medicine, 118, 557ą561.

Lazarou, Jason, Pomeranz, Bruce H, \& Corey, Paul N. (1998). Incidence of adverse drug reactions in hospitalized patients: a meta-analysis of prospective studies. Jama, 279(15), 1200-1205.

Lee, Grace C, Reveles, Kelly R, Attridge, Russell T, Lawson, Kenneth A, Mansi, Ishak A, Lewis, James S, \& Frei, Christopher R. (2014). Outpatient antibiotic prescribing in the United States: 2000 to 2010. BMC medicine, 12(1), 96.

Levy, R. (1994). The role and value of pharmaceutical marketing. Archives of family medicine, 3(4), 327-332.

Lopez-Vazquez, Paula, Vazquez-Lago, Juan M, \& Figueiras, Adolfo. (2012). Misprescription of antibiotics in primary care: a critical systematic review of its determinants. Journal of evaluation in clinical practice, 18(2), 473-484.

Malik, Fazal, Asif, Muhammad, \& Wali, Said. (2016). Role of Social Media on Consumer Preferences. City University Research Journal, 6(02), 256-268.

Malik, Fazle. (2019). Exploring the Role of Pharmaceutical Marketing on Physician Ethical Behaviors: A Grounded Theory Study. CITY UNIVERSITY RESEARCH JOURNAL, 9(2).

McCaig, Linda F, Besser, Richard E, \& Hughes, James M. (2002). Trends in antimicrobial prescribing rates for children and adolescents. Jama, 287(23), 30963102.

McCaig, Linda F, Besser, Richard E, \& Hughes, James M. (2003). Antimicrobial-drug prescription in ambulatory care settings, United States, 1992-2000. Emerging infectious diseases, 9(4), 432.

McCaig, Linda F, Hooker, Roderick S, Sekscenski, Edward S, \& Woodwell, David A. (1998). Physician assistants and nurse practitioners in hospital outpatient departments, 1993-1994. Public health reports, 113(1), 75.

Mizik, Natalie, \& Jacobson, Robert. (2004). Are Physicians "Easy Marks"? Quantifying the Effects of Detailing and Sampling on New Prescriptions. Management Science, 50(12), 1704-1715. doi: 10.1287/mnsc.1040.0281

Moghaddam, Alireza. (2006). Coding issues in grounded theory. Issues in educational research, 16(1), 52-66.

Moynihan. (2002). Selling sickness: the pharmaceutical industry and disease mongeringCommentary: Medicalisation of risk factors. Bmj, 324(7342), 886-891.

Moynihan. (2008). Key opinion leaders: independent experts or drug representatives in disguise? BMJ, 336(7658), 1402-1403. doi: 10.1136/bmj.39575.675787.651

Narendran, Roshni, \& Narendranathan, M. (2013). Influence of pharmaceutical marketing on prescription practices of physicians. 
Nerlich, Brigitte, \& James, Richard. (2009). "The post-antibiotic apocalypse" and the "war on superbugs": catastrophe discourse in microbiology, its rhetorical form and political function. Public Understanding of Science, 18(5), 574-590.

Olivier, Catherine, Williams-Jones, Bryn, Doize, Beatrice, \& Ozdemir, Vural. (2010). Containing global antibiotic resistance: ethical drug promotion in the developing world Antimicrobial Resistance in Developing Countries (pp. 505-524): Springer.

Patton, Michael Quinn. (2002). Two Decades of Developments in Qualitative Inquiry:A Personal, Experiential Perspective. Qualitative Social Work, 1(3), 261-283. doi: $10.1177 / 1473325002001003636$

Peattie, Ken, \& Peattie, Sue. (2009). Social marketing: A pathway to consumption reduction? Journal of Business Research, 62(2), 260-268. doi: https://doi.org/10.1016/j.jbusres.2008.01.033

Peay, Marilyn Y, \& Peay, Edmund R. (1988). The role of commercial sources in the adoption of a new drug. Social science \& medicine, 26(12), 1183-1189.

Power, E. (2006). Impact of antibiotic restrictions: the pharmaceutical perspective. Clinical Microbiology and Infection, 12, 25-34.

Rabin, R. (2003). Caution about overuse of antibiotics. Newsday. September 18, 2003. 2a, Centers for Diseases Control and Prevention. CDC antimicrobial resistance and antibiotic resistance-general information.

Relman, A. S. (2001). Separating continuing medical education from pharmaceutical marketing. JAMA, 285(15), 2009-2012. doi: 10.1001/jama.285.15.2009

Scherer, F. M. (2000). Chapter 25 The pharmaceutical industry Handbook of Health Economics (Vol. 1, pp. 1297-1336): Elsevier.

Schmid, Harriet. (1981). Qualitative research and occupational therapy. Amer J Occup Ther, 35(2), 105-106.

Sengupta, Saswati, \& Chattopadhyay, Madhab K. (2012). Antibiotic resistance of bacteria: A global challenge. Resonance, 17(2), 177-191.

Silver, Lynn L, \& Bostian, KA. (1993). Discovery and development of new antibiotics: the problem of antibiotic resistance. Antimicrobial agents and chemotherapy, 37(3), 377.

Slomski, Anita. (2016). Reducing Unnecessary Antibiotic PrescriptionsReducing Antibiotic PrescriptionsClinical Trials Update. JAMA, 315(16), 1693-1693. doi: 10.1001/jama.2016.4590

Spielmans, Glen I., \& Parry, Peter I. (2010). From Evidence-based Medicine to Marketing-based Medicine: Evidence from Internal Industry Documents. Journal of Bioethical Inquiry, 7(1), 13-29. doi: 10.1007/s11673-010-9208-8

Strauss, \& Corbin. (1998). Basics of qualitative research techniques: Sage publications Thousand Oaks, CA.

Sufrin, Carolyn B, \& Ross, Joseph S. (2008). Pharmaceutical industry marketing: Understanding its impact on women's health. Obstetrical \& gynecological survey, 63(9), 585-596.

Tomson, Göran, \& Sterky, Göran. (1986). Self-prescribing by way of pharmacies in three Asian developing countries. The Lancet, 328(8507), 620-622.

Trostle, James. (1996). Inappropriate distribution of medicines by professionals in developing countries. Social Science and Medicine, 42(8), 1117-1120. 
Usluer, Gaye, Ozgunes, Ilhan, \& Leblebicioglu, Hakan. (2005). A multicenter pointprevalence study: antimicrobial prescription frequencies in hospitalized patients in Turkey. Annals of clinical Microbiology and Antimicrobials, 4(1), 16.

Van De Sande-Bruinsma, Nienke, Grundmann, Hajo, Verloo, Didier, Tiemersma, Edine, Monen, Jos, Goossens, Herman, .. . System, European Antimicrobial Resistance Surveillance. (2008). Antimicrobial drug use and resistance in Europe. Emerging infectious diseases, 14(11), 1722.

van den Bogaard, Anthony E, \& Stobberingh, Ellen E. (2000). Epidemiology of resistance to antibiotics: links between animals and humans. International journal of antimicrobial agents, 14(4), 327-335.

Venter, Henrietta, Henningsen, Michael L, \& Begg, Stephanie L. (2017). Antimicrobial resistance in healthcare, agriculture and the environment: the biochemistry behind the headlines. Essays in biochemistry, 61(1), 1-10.

Wager, Elizabeth. (2003). How to dance with porcupines: rules and guidelines on doctors' relations with drug companies. BMJ : British Medical Journal, 326(7400), 11961198.

Washer, Peter, \& Joffe, Helene. (2006). The "hospital superbug": social representations of MRSA. Social Science \& Medicine, 63(8), 2141-2152.

Wazana, A. (2000). Physicians and the pharmaceutical industry: Is a gift ever just a gift? JAMA, 283(3), 373-380. doi: 10.1001/jama.283.3.373

WHO. (1988). Ethical criteria for medicinal drug promotion.

WHO. (2005). Drug promotion: what we know, what we have yet to learn: reviews of materials in the WHO/HAI database on drug promotion: World Health Organization.

WHO. (2018). Global antimicrobial resistance surveillance system( GLASS) report: early implementation 2017-2018.

Wininger, Phillip J. (2004). Pharmaceutical overpromotion liability: the legal battle over rural prescription drug abuse. Ky. $L J, 93,269$.

Wozniak, Teresa M., Bailey, Emily J., \& Graves, Nicholas. (2019). Health and economic burden of antimicrobial-resistant infections in Australian hospitals: a populationbased model. Infection Control \& Hospital Epidemiology, 40(3), 320-327. doi: 10.1017/ice.2019.2

Wright, Gerard D. (2000). Resisting resistance: new chemical strategies for battling superbugs. Chemistry \& biology, 7(6), R127-R132.

Zhang, Yuting, Steinman, Michael A., \& Kaplan, Cameron M. (2012). Geographic Variation in Outpatient Antibiotic Prescribing Among Older AdultsGeographic Variation in Antibiotic Prescribing. JAMA Internal Medicine, 172(19), 14651471. doi: 10.1001/archinternmed.2012.3717 